\title{
ANNOTATION
}

\section{One-eyed Drivers}

A report on one-eyed drivers appeared in the issue of the Sightsaving Review of November, 1938, by three Research Associates in the Institute of Human Relations at Yale University. It appears that in the United States one to two per cent. of drivers are totally blind in one eye, while between 20 and 40 per cent. have a deficient eye which handicaps them. No State prohibits either group from driving. "Only about 20 States make any check on vision for the driver's licence, and there is no agreement regarding visual standards." The authors of this report conclude that "most oneeyed and deficient-eyed drivers are oblivious to the defects which predispose them to accidents. For most of these drivers the solution lies in personal re-education adapted to their individual needs, for the greatest human hazard arises not from the defects but from ignorance of the dangers from such defects."

The one-eyed driver is particularly handicapped in night driving. $\mathrm{He}$ is more sensitive to glare and it takes him longer to recover from the glare and to see the road clearly again. The loss of binocular field can be compensated to a certain degree by keeping the head turned at a small angle, but the position is to a certain extent awkward and strained and would be likely, we think, to lead to fatigue of the neck muscles. "Another form of correction possible is to keep the head and the eyes roving continually from right to left while driving in order to bring possible dangers from the side into the field of vision of the good eye."

The report ends with tables of hazards to which the left-eyed and right-eyed persons are exposed. It must be remembered that in the United States the driver sits on the left-hand side and drives on the right side of the road.

We have no hesitation in commenting on vision in motoring in spite of an annotation on this subject last year. The matter is of the greatest importance in view of the tragedy of the roads. That there is nothing to stop the one-eyed driver from obtaining a licence seems to us to indicate that the question of vision was not sufficiently considered when the rules were drawn up. The fact that Hannibal, who was uniocular, crossed the Alps, cannot be considered an argument in favour of the one-eyed driver, for we believe his form of transport was the elephant, which. if as powerful in some respects as the modern motor engine certainly never achieved anything like the speed attained at the present day. We are inclined to think that a one-eyed person should not be granted a licence. With regard to the driver with one defective eye we think that the advantage 
of a binocular field probably compensates for lack of macular acuity and we see no reason why such a person should be debarred from driving. This report will have done good if it calls the attention of the authorities in the States to the importance of the subject, and we will end with the pious hope that it will soon be as difficult to find a one-eyed driver in America as it was to find a dead postboy in the old coaching days in England.

\section{ABSTRACTS}

\section{I.-GLAUCOMA}

(1) Magitot, A. - Glaucoma without rise of pressure. (Glaucomes sans hypertension). Ann. d'Ocul., Vol. CLXXV, p. 349, May, 1938.

(1) Magitot is of opinion, that the disease which A. v. Graefe has labelled amaurosis with excavation, should be classified into three groups :-

(a) Myopic glaucoma according to the conceptions of Axenfeld.

(b) Very chronic glaucoma with only occasional rise of the intraocular pressure. The disc may or may not show cupping.

(c) A third group, which presents a deep atrophic cupping. Here, the word glaucoma is probably a misnomer, and the old name amaurosis with excavation is more adequate. Pressure of the sclerosed carotids on the chiasma or on the optic nerves has been suspected as the cause of this atrophy. However, the author is not fully satisfied with Thiel's radiographic evidence of sclerosis of the intracranial carotids. The proof is still wanting, that sclerosis of the carotids or of the anterior cerebral artery does result in atrophic cupping. Many old people, whose carotids offer the same radiographic aspect, do not show an attophic excavation. Further, tumours of the hypophysis undoubtedly exercise a considerable pressure on the chiasma and the optic nerves; nevertheless, the consequent optic atrophy is only exceptionally associated with excavation.

\section{HUMPHREY NeAME.}

(2) Malling, B. (Bergen).-Investigations on the so-called giaucoma capsulare. (Einige Untersuchungen ueber das sogenannte Kapselglaukom). Acta Ophthal., Vol. XVI, p. 43, 1938.

(2) Malling investigated 181 patients suffering from glaucoma simplex and found that the deposits on the posterior aspect of the cornea which are regarded as characteristic of capsular glaucoma, 